\title{
RBEP
}

\section{Tessitura e subsídios de um produto literário infantojuvenil para o ensino da história e da cultura africana e afro-brasileira}

Thiago Leandro da Silva Dias ${ }^{\mathrm{I}, \mathrm{II}}$

Rogério Santos Souza ${ }^{\text {III,IV }}$

https://dx.doi.org/10.24109/2176-6681.rbep.102i261.4260

\section{Resumo}

Considerando a potencialidade do uso de literatura infantojuvenil na perspectiva de uma educação das relações étnico-raciais, em consonância com a Lei no ${ }^{\circ} 10.639 / 2003$, o conto O terreiro de vovó Estela, nosso pedacinho de África foi escrito com o objetivo de apresentar a história de Luanda e sua avó, Estela, que cultiva/cultua em seu quintal folhas que curam, usadas em rezas, chás, banhos e defumações. Projetando sua publicação e circulação em diferentes espaços educativos, é importante reconhecer a necessidade de submetermos seu conteúdo para avaliação de atores sociais. Assim, objetivamos avaliar o referido conto a partir da sua recepção por um grupo de professores(as), escritores(as) e pesquisadores(as). O formato avaliativo da recepção foi feito mediante um processo de validação de conteúdo, em que foi possível dimensionar melhor as possibilidades de uso, as críticas e as modificações da escrita, da linguagem, do alcance e do público-alvo. O conto foi avaliado e devidamente validado pelos(as) especialistas participantes, com contribuições significativas para a educação das relações étnico-raciais e o ensino da história e da cultura africana e afro-brasileira.

Palavras-chave: diáspora africana; recepção literária; relações étnicoraciais.

\footnotetext{
Universidade Federal do Recôncavo da Bahia (UFRB). Feira de Santana, Bahia, Brasil. E-mail:<thiagodias@ ufrb.edu.br >; <https://orcid. org/0000-0003-3393-4566>.

II Mestre em Ensino, Filosofia e História das Ciências pela Universidade Federal da Bahia (UFBA), Salvador, Bahia, Brasil e Universidade Estadual de Feira de Santana (UEFS), Feira de Santana, Bahia, Brasil.

III Universidade Federal do Recôncavo da Bahia (UFRB). Santo Amaro, Bahia, Brasil. E-mail:<rg. edu.souza@gmail. com>; <https://orcid. org/0000-0002-4934-3026>.

IV Mestre em História da África, da Diáspora e dos Povos Indígenas pela Universidade Federal do Recôncavo da Bahia (UFRB). Cachoeira, Bahia, Brasil.
} 


\section{Abstract \\ Weaving and subsidizing a children and youth's literary product for the teaching of African and afro-Brazilian history and culture}

There are potentialities in the use of children and youth's literature in the perspective of the education of ethnic-racial relations, as proposed in the Brazilian legal document Lei ${ }^{\circ} 10.639 / 2003$. Therefore, the tale Grandma Estela's terreiro, our little piece of Africa was written to introduce the story of Luanda and her grandmother Estela, who grows healing leaves in her backyard; which are used for prayers, teas, baths and smoking. While propelling its publication and circulation in different educational spaces, it is important to acknowledge that its content must be submitted to social actors for evaluation. Thus, this study aims to evaluate the tale from its reception by a group of teachers, writers and researchers. The evaluation format for the reception was developed through a content validation process, in which it was possible to better measure the possibilities for use, criticism and changes in writing, language, scope and target audience. The story was evaluated and duly validated by specialists, who have significantly contributed for the education of ethnic-racial relations and the teaching of African and afro-Brazilian history and culture.

Keywords: African diaspora; ethnic-racial relations; literary reception.

\section{Resumen \\ Tejeduría y subsidios de un producto literario infantil y juvenil para la enseñanza de la historia y cultura africana y afrobrasileña}

Considerando el potencial del uso de la literatura infantil y juvenil en la perspectiva de una educación de las relaciones étnico-raciales, en consonancia con la Ley $n .{ }^{\circ} 10.639 / 2003$, el cuento El terreiro de la abuelita Estela, nuestro pedacito de Africa fue escrito con el objetivo de presentar la historia de Luanda y su abuela, Estela, que cultiva, en su patio trasero, hojas que curan, usadas en oraciones, tés, baños y para ahumar. Al proyectar su publicación y circulación en diferentes espacios educativos, es importante reconocer la necesidad de presentar su contenido para su evaluación por parte de los actores sociales. Por lo tanto, nuestro objetivo es evaluar el cuento referido desde su recepción por un grupo de profesores, escritores e investigadores. El formato de evaluación de la recepción se realizó por medio de un proceso de validación de contenido, en el que fue posible medir mejor las posibilidades de uso, la crítica y los cambios de la escritura, del lenguaje, del alcance y del público objetivo. La historia fue evaluada y debidamente validada por los especialistas participantes, con importantes contribuciones a la educación de las relaciones étnico-raciales y la enseñanza de la historia y de la cultura africana y afrobrasileña.

Palabras clave: diáspora africana; recepción literaria; relaciones étnicoraciales. 


\section{Introdução}

Configurados como demanda para todas as áreas do conhecimento, além de envolver a articulação entre processos educativos escolares, políticas públicas e movimentos sociais, os conteúdos referentes à história e à cultura africana, afro-brasileira e indígena devem ser ministrados no âmbito de todo o currículo escolar. Essa obrigatoriedade em efetivar uma educação das relações étnico-raciais está presente no artigo 26-A da Lei de Diretrizes e Bases da Educação (LDB), modificado pela Lei no 10.639/2003 e posteriormente pela Lei $\mathrm{n}^{\circ} 11.645 / 2008$.

Um estudo de nível nacional, organizado por Nilma Lino Gomes (2012), que teve como objetivo analisar iniciativas institucionais que contemplem a problematização das relações étnico-raciais nas escolas, revelou a existência de algumas práticas e posturas pedagógicas contraditórias, que, embora tenham sido apontadas por educadores e gestores responsáveis como práticas desenvolvidas na perspectiva da Lei $n^{\circ}$ 10.639/2003, demonstraram desacordo com princípios e orientações firmados nos dispositivos legais. Esse estudo apontou como alguns dos equívocos dessa natureza as iniciativas descontínuas, fundadas em concepções estereotipadas e racistas sobre a África e os afro-brasileiros, envoltas pelo discurso da democracia racial e da boa vontade (Gomes, 2012).

Um exemplo de inadequações em iniciativas de promoção de educação das relações étnico-raciais é apresentado no estudo de Santana, BaibichFaria e Pessoa (2010), que analisou a implementação da Lei no 10.639/2003 no que tange especificamente ao ensino de Arte em escolas públicas de um município do estado do Paraná. O autor avaliou que as intervenções educacionais voltadas para implementação dessa lei, no contexto educacional da pesquisa, podem ser caracterizadas como uma "folclorização racista", cujas consequências alimentam a afirmação do preconceito ao invés de seu combate. No âmbito da literatura, Pestana (2009) dimensiona processo semelhante ao analisar narrativas que tinham a intenção de denunciar um problema social e acabaram, de fato, por inferiorizar as personagens negras na obra analisada.

Diante de tal conjuntura sobre a possibilidade e a realidade de uma implementação contraditória das leis nas escolas e em outros espaços de educação, e partindo da necessidade de formular indicadores para avaliação dessa implementação (Brasil. MEC, 2009), é de grande relevância o amadurecimento e o desenvolvimento de estratégias metodológicas que sejam capazes de analisar contribuições de iniciativas pedagógicas para educação das relações étnico-raciais, como também a própria formulação e o fortalecimento de práticas educativas, bem como propostas curriculares e materiais didáticos e literários.

Foi com base nessa realidade que o conto $O$ terreiro de vovó Estela, nosso pedacinho de África foi escrito e concebido: como forma de trazer à tona e problematizar as relações étnico-raciais e fortalecer uma educação antirracista que valorize a ancestralidade africana ao desocultar as vozes negras silenciadas nos currículos escolares e nas obras literárias. Ao refletir 
sobre tal compromisso e reiterar a necessidade de se produzir materiais educativos com esse enfoque, sem incorrer em erros e equívocos, propomos a presente investigação e o recorte temático. Assim, desocultar vozes negras perpassa pela necessidade de tessituras literárias em que o "conjunto de notas" dessas vozes presentes na narrativa seja articulado para uma produção com a qualidade necessária à sua execução (afrorreferenciada e antirracista).

Esta pesquisa parte dessas preocupações e proposições, na medida em que pretende elaborar formas avaliativas de um processo de tessitura literária comprometido com as diretrizes legais e políticas para uma educação antirracista, lançando, assim, esforços para compreender o processo de recepção da narrativa por professore(as), escritores(as) e pesquisadores(as), antes de pensar sua divulgação para o público infantojuvenil, podendo, dessa forma, articular possíveis críticas e sugestões para o amadurecimento, a reformulação, o endossamento e a validação da escrita.

A proposta é que, a longo prazo, tal narrativa seja apresentada em escolas e terreiros de Candomblé. No entanto, antes dessa etapa se concretizar, é importante reconhecer a necessidade de levarmos a narrativa para avaliação de atores sociais comprometidos com a implementação e a institucionalização das Leis no 10.639/2003 e no 11.645/2008, na perspectiva de validar seu conteúdo e tecer críticas relevantes para sua divulgação e publicação. Assim, objetivamos, com este trabalho, avaliar o conto $O$ terreiro de vovó Estela, nosso pedacinho de África, levando em conta a recepção literária de especialistas.

\section{Do silêncio à desocultação de vozes negras na literatura infantojuvenil}

A linguagem, especialmente como discurso, é sempre expressão de um poder. É dessa reflexão que parte Francisco Noa (2009) ao afirmar que, do ponto de vista literário, essa expressão reside no poder de enunciar, de nomear, de criar mundos, de instituir, de manipular e de validar vozes. Nesse sentido, a literatura pode ser vista como espaço de sonegação, silenciamento, sujeição, marginalização e opressão de determinados sujeitos e grupos sociais, assim como de empoderamento, representatividade, identidade e resistência dos(as) subalternizados(as).

Quer como objeto de representação, quer como sujeito de enunciação, as vozes dos(as) negros(as) que foram emergindo, tardiamente, na história da literatura brasileira, concorreram mais para vincar a sua verdadeira condição do que para legitimar a multiplicidade e a diversidade de falas de que esse sistema se deveria revestir (Noa, 2009). Esse lugar comum de sub-representação e de silenciamento é norma não só na produção literária, mas em todo contexto de produção intelectual em que o(a) negro(a), quando não subjugado(a) por essência, tem sua voz revestida por um conjunto de estratégias e práticas que impossibilitam a narração da sua própria história, das suas epistemologias, cosmologias e diversas práticas socioculturais, 
muitas vezes, resumindo a contribuição do povo negro ao nível folclórico e/ou caricatural.

A ocultação das vozes negras (autores, autoras, personagens e seus saberes referenciados) na literatura brasileira é um silêncio que permeia vários espaços sociais e de poder, como consequência de classificação e hierarquização racial construídas historicamente, desde a colonização, na efervescência das relações sociais, e que passaram a regular as relações étnico-raciais como mais uma lógica desenvolvida no interior da nossa sociedade (Gomes, 2003). À vista disso, os espaços escolares e o sistema educacional brasileiro forjaram-se como instrumentos de reprodução e legitimação de discriminação racial, de preconceito e de racismo ao longo da história, que se proliferam na medida em que se silencia qualquer voz dissidente.

No estudo de Eliane Cavalleiro (2000), por exemplo, na escola e nas famílias, verificou-se a predominância do silêncio nas situações que envolvem racismo, preconceito e discriminação étnicos, o que permite supor que a criança negra, desde a educação infantil, está sendo socializada para o silêncio e para a submissão. Mais grave ainda é o fato de que a criança negra está sendo levada a se conformar com o lugar que lhe é atribuído: o lugar do rejeitado, o de menor valia. Como reitera a autora, ao inferir que:

[...] o silêncio que atravessa os conflitos étnicos na sociedade é o mesmo que sustenta o preconceito e a discriminação no interior da escola. Como aos negros estão reservados, na sociedade, papel e lugar inferiores, pode-se afirmar que essa linguagem o condiciona ao fracasso, à submissão e ao medo, visto que parte das experiências vividas na escola é marcada por humilhações (Cavalleiro, 2000, p. 98).

Tal realidade tem, no âmbito do livro didático, ressonância e ratificação, como bem pontua Ana Célia da Silva $(2004,2005)$, ao afirmar que, de modo geral, o livro didático omite o processo histórico e cultural, o cotidiano e as experiências dos segmentos subalternizados da sociedade, como o(a) negro(a), o(a) indígena, a mulher, entre outros. Em relação ao indivíduo negro, "sua quase total ausência nos livros e a sua rara presença de forma estereotipada concorrem, em grande parte para o recalque de sua identidade e autoestima" (Silva, 2004, p. 51).

Situando o contexto histórico e curricular de ocultações das vozes e das narrativas negras na literatura e em todo sistema de ensino, que persistem até a atualidade, bem como a estratégia de perdurar o colonialismo/ eurocentrismo como mecanismo de manutenção, parece-nos importante, necessário e legítimo pensar formas de trazer à tona e reverberar a diversa produção literária negra e afro-brasileira, no sentido que sugere Noa (2009), de desocultação das vozes ocultas e silenciadas dos(as) subalternizados(as) e oprimidos(as), firmando assim "um contra-discurso à literatura produzida pela cultura hegemônica" (Evaristo, 2009, p. 27) e à educação de referência eurocêntrica e colonial.

Além de toda produção literária negra e afro-brasileira, destacamos a literatura infantojuvenil como um importante ato de desocultação, de restituição de vozes e falas reprimidas, omissas e usurpadas, por ser 
destinada principalmente para a educação de crianças e jovens; para a juventude, nosso futuro e esperança de emancipação. Como reiteram Souza, Sousa e Pires (2005), a leitura da literatura infantojuvenil pode contribuir para a promoção da igualdade étnico-racial em ambientes educativos. Essa é uma das bandeiras há muito levantada por ativistas do movimento negro, educadores(as) e pesquisadores(as) envolvidos(as) com a desocultação de vozes, valores e identidades negras na diáspora.

Diante de tal realidade, urge a necessidade de nos atentarmos, ainda mais, para a produção literária destinada às crianças e aos jovens do nosso País (Oliveira, 2014). Tal atenção requer um olhar mais crítico e menos ingênuo sobre a referida produção, como reitera a autora, já que estamos levando em conta:

[...] a possibilidade de ressignificação e valorização na tessitura literária, ao delinear os negros e, negras em diversos papeis e/ou espaços sociais, sem restringir a uma África e/ou diáspora cujo império é o da pobreza, da criminalidade, das disputas e consequente desumanização (Oliveira, 2014, p. 146).

É nesse fluxo literário que encontramos uma gama de produções sobre Áfricas e diásporas no âmbito da literatura infantil e juvenil, que podem e devem ser utilizadas como recurso didático para estimular diversos processos de ensino e aprendizado, com incentivo à leitura, à escrita e levando em consideração as variadas nuances da construção de identidade e de alteridade.

Na contramão de tal inovação, encontramos ainda algumas obras que reforçam ideias racistas, infelizmente. Na pesquisa de Maria Anória Oliveira (2008) sobre análise de narrativas afro-brasileiras infantojuvenis contemporâneas, por exemplo, em uma das obras literárias que a autora analisou, contraditoriamente são reforçados ideários racistas seculares:

[...] ao final do livro há a associação 'coração claro: leite', referindo-se à bondade do espírito dos antepassados negros. E, ao contrário, o 'Céu negro', associado a algo 'pesado': o 'ar irrespirável', no caso e 'a seca'. A partir desse pequeno exemplo podemos notar que, mesmo em uma obra que traz à tona a cosmovisão africana e seu espaço social, em $A$ áfrica, meu pequeno Chakase deixa a desejar, por conta da associação: positividade/branco (associado ao leite, alimento vital ao ser humano, à espiritualidade, na obra) e, ao contrário: negro/negatividade/morte (carência de água, sem a qual o ser humano morre, ficando 'sem ar', sufocado) (Oliveira, 2008, p. 6).

No âmbito geral da educação, alguns autores também nos alertam sobre a implementação equivocada das Leis $\mathrm{n}^{\circ}$ 10.639/2003 e $\mathrm{n}^{\circ}$ 11.645/2008 em contextos de ensino (Santana, Baibich-Faria; Pessoa, 2010; Gomes, 2012) cujas consequências alimentam a afirmação do preconceito ao invés de seu combate. A permanência de tais impasses para desocultação de vozes negras na literatura infantojuvenil e na educação demanda uma junção de esforços canalizados para produção, avaliação e revisão de narrativas literárias voltadas para o contexto de ensino, de obras infantojuvenis cuja tessitura visa à valorização e à ressignificação das raízes africanas, reinventando a África, suas tradições e recriando o presente do povo negro na diáspora, por meio do processo de ficcionalizar essas raízes (Oliveira, 2010). 


\section{Recepção de narrativas literárias: aspectos metodológicos}

Para dar conta dos objetivos elencados, esta investigação filia-se a uma abordagem qualitativa (Creswell, 2010), envolvendo uma pesquisa de natureza aplicada (Fleury; Werlang; 2017). Sob o ponto de vista dos procedimentos, adotamos como orientação geral a pesquisa-ação, que, na perspectiva educacional, é principalmente uma estratégia para o desenvolvimento de professores(as) e pesquisadores(as) de modo que eles(as) possam utilizar suas pesquisas para aprimorar o ensino e o aprendizado (Tripp, 2005). A mudança/inovação é o impulso de uma pesquisa de ação; o processo de projetar ações (intervenções na situação social) aprofunda nos participantes a compreensão dos processos sociais e desenvolve novas estratégias para induzir melhorias (Noffke; Bridget, 2005).

Este trabalho de pesquisa é uma das etapas do processo de pesquisaação, que pretende se estender em estudos futuros, de modo a não só analisar, mas, sobretudo, estimular e fortalecer o uso da narrativa em espaços/momentos educativos por diferentes atores e atrizes sociais e em variados contextos pedagógicos.

Com a intenção de garantir a qualidade do produto coautoral e maximizar sua credibilidade, propomos um processo de recepção literária a fim de instrumentalizar a validação de conteúdo, que consiste em julgar a proporção em que os itens selecionados para avaliar uma construção teórica e/ou metodológica representam as facetas importantes de um determinado conceito, tema, estratégia ou abordagem. Um dos procedimentos normalmente empregados para validar o conteúdo é o parecer de juízes; tarefa para a qual especialistas são requisitados e emitem sua avaliação sobre a adequação aparente entre o instrumento proposto e a construção a ser validada (Pasquali, 2009; Pilatti; Pedroso; Gutierrez, 2010; Raymundo, 2009). Como procedimento de coleta de dados, criamos estratégias para estimular a avaliação do produto juntamente com professores(as), escritores(as) e pesquisadores(as), o que envolveu, primeiramente, a construção do instrumento de validação, contendo informações sobre a pesquisa e os espaços destinados para coleta de dados sobre o(a) avaliador(a)/especialista, os itens avaliativos do material distribuídos em tópicos e uma questão optativa para um parecer escrito. O instrumento foi enviado juntamente com o conto para os(as) participantes, via correio eletrônico.

As possibilidades de respostas às questões (itens) foram apresentadas em escala tipo Likert para indicação do grau de concordância com a afirmação, considerando-se as seguintes categorias: inadequado, parcialmente adequado, adequado, totalmente adequado e não se aplica. A escala de verificação de Likert consiste em tomar um construto e desenvolver um conjunto de afirmações relacionadas à sua definição, para as quais os respondentes emitirão seu grau de concordância (Silva Júnior; Costa, 2014). 
Para análise dos dados e validação do conto, foram utilizadas duas estratégias de validação dos itens, levando em consideração trabalhos sobre construção e validação de materiais educativos (Teles et al., 2014; Nobre, 2018). A primeira considera validado um determinado item quando este obtém a classificação de totalmente adequado por pelo menos metade mais um do número de especialistas, e os(as) outros(as) especialistas não o consideram totalmente inadequado. $\mathrm{O}$ item também é considerado validado quando os(as) especialistas o consideram parcialmente adequado ou inadequado, mas apresentam sugestões de melhoria que são inseridas no material. A segunda estratégia para validação dos itens foi a apresentação de índice de validade de conteúdo (IVC) maior ou igual a 0,78. O IVC mede a proporção de juízes que estão em concordância sobre determinados aspectos do instrumento e de seus itens (Teles et al., 2014).

A escolha dos(as) participantes da pesquisa foi feita mediante o envolvimento de cada um(a) com a produção, o ensino e/ou a pesquisa de materiais educativos e/ou literários voltados para o público infantojuvenil. Sendo assim, convidamos professores(as), pesquisadores(as) e escritores(as) como forma de abranger uma diversidade de sujeitos, o que potencializa a avaliação e a projeção de melhorias na escrita e na composição da narrativa. Os dados oriundos da etapa de validação serão analisados, com vistas ao fomento de uma futura revisão crítica do material, nos desdobramentos desta pesquisa-ação.

Levando em consideração os aspectos éticos na pesquisa, para preservar as identidades dos(as) especialistas leitores(as), foram adotados nomes fictícios na divulgação de suas falas avaliativas. Cada leitor(a) que teceu comentários escritos recebeu o nome de um país africano com influências étnicas e linguísticas Bantu, para simbolicamente afrorreferenciar nossa pesquisa. Atentamos ainda para que a investigação estivesse ininterruptamente submetida ao rigor dos princípios éticos que devem pautar a pesquisa envolvendo seres humanos, garantindo a estabilidade e a confiabilidade nas relações vivenciadas no contexto analisado.

\section{Contextualizando a tessitura da narrativa}

Os movimentos de escrita, pesquisa, memória e produção de narrativas nos trazem a noção de quão relevantes são/foram a intertextualidade e os seus modos de constituição na concepção e na tessitura do conto. Em sentido amplo, a intertextualidade se faz presente em todo e qualquer texto como componente decisivo de suas condições de produção. Segundo Koch e Elias (2006, p. 86), "é elemento constituinte e constitutivo do processo de escrita/leitura" e compreende as diversas maneiras pelas quais a produção/ recepção de um dado texto depende dos diversos tipos de relações que ele mantém com outros textos. Assim, dialogamos ao longo dessa trajetória de 
escrita coautoral com variadas fontes (bibliográficas, literárias, afetivas, políticas) que deram origem ao intertexto.

A relevância de pensar e pôr em prática a intertextualidade na tessitura da obra em questão leva em consideração que esta pode ser analisada como um instrumento da memória cultural em "um exercício que supera a categorização e a fixidez para enfatizar o perfil mutável, posicional, duplo e ambíguo de reconstrução de memórias a partir do texto literário" (Freitas, 2015, p. 42). O que Ivana Freitas denomina de intertextualidade das memórias, já que reescrever, rememorar e retomar as contribuições das matrizes africanas no Brasil é um trabalho de reinvenção que consiste em escavar e fazer emergir relatos historicamente silenciados (Freitas, 2015).

Assim, Luanda e vovó Estela nasceram da vivência literária de dois discentes durante um curso de pós-graduação em Estudos Étnicos e Raciais. Além das motivações a nível de temática e compromisso pedagógico e político, dois contextos influenciaram por demasia o início da escrita: a escola e o terreiro. Espaços de vivência dos autores que auxiliaram no entendimento do conjunto de fatores que determinam a produção de linguagem - contexto, condições de produção e situação de enunciação quem fala, com quem, quando, onde, em que condições, com que propósito etc. (Koch; Elias, 2006). A composição foi embasada também por uma rotina de estudos e por um esforço de teorizar aquilo que escrevíamos, de modo a colocar em pauta nossa produção, com o objetivo de melhorar e afinar a tessitura conforme as diretrizes e as orientações teórico-metodológicas. Nesse sentido, além da escrita em si, publicamos e apresentamos alguns trabalhos acadêmicos correlacionados com nossa narrativa (Dias; Souza, 2017, 2018; Dias, 2019), buscando colher opiniões e críticas externas relevantes para validação.

O conto O terreiro de vovó Estela, nosso pedacinho de África aborda a história de Luanda e sua avó, Estela, que guarda em seu quintal folhas que curam, usadas em rezas, chás, banhos e defumações. Luanda compartilha essas histórias na escola depois de ter se curado de uma grande dor de barriga, e todos vão ao terreiro/quintal da avó para conhecer o segredo dessas folhas sagradas e ouvir histórias sobre ancestralidade africana e preservação da natureza. O conto aborda ainda questões como racismo religioso, musicalidade e diáspora, imbricando mitologia, religiosidade e valores de matrizes africanas, elementos constitutivos em face da tessitura de personagens e protagonistas negros(as) na literatura infantojuvenil.

\section{Recepção literária e validação de conteúdo: principais resultados}

O texto é um potencial de efeitos que se atualiza no processo da leitura. Logo, ele se realiza por meio da constituição de uma consciência receptora. Desse modo, é só na leitura que a obra, enquanto processo, 
adquire seu caráter próprio (Iser, 1996). O leitor, ao se aproximar do texto, traz suas disposições individuais, seu referencial literário, linguístico, social e ideológico. A estética da recepção aposta na ação do leitor, pois dele depende a concretização do projeto de emancipação que justifica a existência das criações literárias (Zilberman, 2008).

Em função dessa relevância atribuída ao/à leitor(a) e à leitura no processo de produção de textos, escolhemos como sujeitos(as) leitores(as) para avaliação da narrativa produzida (recepção literária): escritores(as), professores(as) e pesquisadores(as). Esse movimento de análise permite a um(a) autor(a), por exemplo, estabelecer um elo mais consistente com sua obra; sobretudo porque, conforme declara Iser (1996), ela deve passar por um acentuado grau de exame no ato da leitura.

Para sistematizar esse processo receptivo, realizamos um estudo de validação do conteúdo literário a partir da avaliação dos(as) leitores(as). A seguir, veremos os principais resultados dessa etapa da pesquisa. Segundo Nobre (2018), o processo de validação é essencial após a elaboração de materiais educativos, tendo em vista a necessidade de que sujeitos com experiência no assunto avaliem o material e façam sugestões para o seu aperfeiçoamento. Além disso, sabe-se que a participação de juízes no processo de validação pode elevar a aceitação e a adesão do público-alvo na utilização de materiais educativos (Teles et al., 2014; Nobre, 2018).

Foram convidados(as) 30 especialistas, dos(as) quais 13 retornaram contato, leram o conto e responderam o instrumento de validação, sendo a maioria do gênero feminino (nove), com declaração étnico-racial negra (11) e com maior predominância da faixa etária dos 20 aos 30 anos. Quanto à formação, quatro são pedagogos(as), quatro são historiadores(as), três são biólogos(as), um(a) é museólogo(a) e um(a) é filósofo(a). Quatro participantes possuem especialização e cinco são mestres(as) e/ou mestrandos(as). Infelizmente não contamos com retorno e participação de sujeitos da área de Letras/Linguagens, o que qualificaria ainda mais a avaliação pretendida.

A maioria dos(as) especialistas tem atuação na docência. Quatro participantes têm envolvimento com escrita e criação literária com recorte étnico-racial, e dos nove especialistas que possuem pós-graduação concluída ou em andamento, cinco possuem relação direta com os estudos étnicos e raciais.

No processo de validação do referido material literário, os(as) juízes(as)/leitores(as) avaliaram três aspectos em conjunto: i) conteúdo e objetivo; ii) estrutura e linguagem; e iii) potencial e relevância, indicando níveis de concordância para os itens dispostos em cada um desses aspectos (Tabela 1). Utilizamos o IVC como método para quantificar o grau de concordância entre os especialistas durante o processo de avaliação da validade de conteúdo do material e como forma de substanciar a interpretação dos resultados. Assim, calculou-se o IVC de cada item, o IVC dos aspectos e o IVC global do material. 
Tabela 1 - Níveis de concordância dos(as) juízes(as)/leitores(as), segundo os critérios de validação

\begin{tabular}{|c|c|c|c|c|c|c|}
\hline Itens & \multicolumn{6}{|c|}{ Validação } \\
\hline Conteúdo e objetivo & I & PA & A & TA & NA & IVC \\
\hline $\begin{array}{l}\text { 1.1 Atende aos objetivos e diretrizes para } \\
\text { o ensino de história e cultura africana e } \\
\text { afro-brasileira. }\end{array}$ & & & 3 & 10 & & 1,00 \\
\hline $\begin{array}{l}1.2 \text { E coerente em relação aos conteúdos } \\
\text { abordados. }\end{array}$ & & 1 & 3 & 9 & & 0,92 \\
\hline $\begin{array}{l}\text { 1.3 E um recurso didático para } \\
\text { construção e fortalecimento de identidade } \\
\text { étnico-racial. }\end{array}$ & & 1 & 1 & 11 & & 0,92 \\
\hline $\begin{array}{l}\text { 1.4 Compreende um material educativo } \\
\text { para o ensino de Ciências, História e } \\
\text { Literatura. }\end{array}$ & & 1 & 3 & 9 & & 0,92 \\
\hline \multirow{2}{*}{$\begin{array}{l}\text { 1.5 Proporciona situações de aprendizagem } \\
\text { de fatos, conceitos e comportamentos. }\end{array}$} & & 1 & 5 & 7 & & 0,92 \\
\hline & & & & & & 0,92 \\
\hline Estrutura e linguagem & I & PA & $\mathbf{A}$ & TA & NA & IVC \\
\hline $\begin{array}{l}2.1 \text { O nível de leitura é adequado à } \\
\text { compreensão do leitor. }\end{array}$ & & 4 & 3 & 6 & & 0,69 \\
\hline $\begin{array}{l}\text { 2.1 As informações estão bem } \\
\text { estruturadas em concordância e } \\
\text { ortografia. }\end{array}$ & & & 5 & 8 & & 1,00 \\
\hline $\begin{array}{l}2.3 \text { O estilo de narrativa favorece a } \\
\text { compreensão do leitor. }\end{array}$ & & 1 & 5 & 7 & & 0,92 \\
\hline $\begin{array}{l}2.40 \text { aprendizado é facilitado pela } \\
\text { utilização de tópicos. }\end{array}$ & & 2 & 3 & 6 & 2 & 0,69 \\
\hline 2.5 O número de páginas está adequado. & & 3 & 2 & 8 & & 0,79 \\
\hline \multirow[t]{2}{*}{$\begin{array}{l}\text { 2.6 Possui linguagem clara, compreensível } \\
\text { e adequada para crianças e jovens leitores. }\end{array}$} & & 3 & 2 & 8 & & 0,79 \\
\hline & & & & & & 0,80 \\
\hline Potencial e relevância & I & PA & A & TA & NA & IVC \\
\hline $\begin{array}{l}\text { 3.1 Pode circular nas escolas, terreiros e } \\
\text { outros espaços educativos. }\end{array}$ & & 1 & & 12 & & 0,92 \\
\hline $\begin{array}{l}3.2 \text { Os temas retratam aspectos-chave que } \\
\text { devem ser reforçados. }\end{array}$ & & & 2 & 11 & & 1,00 \\
\hline
\end{tabular}




\begin{tabular}{|c|c|c|c|c|c|}
\hline Itens & \multicolumn{5}{|c|}{ Validação } \\
\hline $\begin{array}{l}3.3 \text { Uso em contexto de ensino, pesquisa } \\
\text { ou extensão. }\end{array}$ & & 1 & 5 & 7 & 0,92 \\
\hline \multirow[t]{2}{*}{$\begin{array}{l}\text { 3.4 Viabilidade da contação de história } \\
\text { para crianças não leitoras. }\end{array}$} & 1 & 2 & 4 & 6 & 0,69 \\
\hline & & & & & 0,84 \\
\hline IVC global & & & & & 0,91 \\
\hline
\end{tabular}

Fonte: Dias (2019, p. 38).

Legenda: I - inadequado; PA - parcialmente adequado; A - adequado; NA - não se aplica; IVC - índice de validade de conteúdo.

\section{Pertinência dos conteúdos e objetivos da narrativa}

Todos os itens da categoria conteúdo e objetivo foram satisfatoriamente avaliados por alcançar um IVC de 0,92 e nenhum item ter sido marcado como inadequado ou não se aplica, não sendo necessário revisar o conteúdo da narrativa para alcançar os objetivos propostos. Vale destacar o valor máximo do IVC para o item 1.1, o que reforça a pertinência de contribuição desse material educativo para o objetivo ao qual se propõe, em consonância com as determinações legais das Diretrizes Curriculares para o Ensino de História e Cultura Africana e Afro-Brasileira. Alguns especialistas teceram comentários que reforçam essa perspectiva educacional a partir da narrativa, ao afirmar, por exemplo, que:

[...] o material tem um excelente potencial educacional, não apenas no sentido de apresentar de maneira leve alguns conceitos, costumes e tradições de religiões afro-brasileiras e aspectos étnicos e raciais, mas também por oferecer um momento de diálogo sobre as questões do preconceito e da intolerância religiosa (Gabão, 2019 apud Dias, 2019, p. 39).

Outros especialistas também avaliaram a contribuição da narrativa no âmbito de conteúdos e temáticas, ressaltando o potencial interdisciplinar que se apresenta. Além da contribuição interpretada com base nos dados quantitativos oriundos da validação, os recortes de escritas e comentários dimensionam melhor, e qualitativamente, a forma como a narrativa tem potencial para o trabalho educativo com questões étnicoraciais, extrapolando os limites disciplinares, que estancam conteúdos em grades, trazendo novas possibilidades didáticas e pedagógicas sensíveis, problematizadoras e transformadoras.

Conforme o estudo de Gevehr e Alves (2016), que avaliou propostas educativas para o ensino de história e cultura afro-brasileira e africana, a interdisciplinaridade permite reafirmar o papel da escola - em consonância com a sociedade em transformação - na superação do racismo, e deve ser ampliada para além das aulas de História.

Outra área com que o produto literário dialoga mais intimamente é a Biologia, por meio dos temas que envolvem conhecimento e uso de 
plantas medicinais, preservação ambiental e relações entre o ser humano, a natureza e a cultura. Uganda (2019 apud Dias, 2019) dimensiona bem essa contribuição para a área:

Sobre o uso em contexto de ensino, pesquisa ou extensão, pontuo que dentro da minha área (biologia/ciências naturais) é possível realizar diversas discussões a partir do conto, por exemplo, a importância dos saberes tradicionais e como esse conhecimento, em muitas ocasiões, serviu e serve de ponto de partida para a ciência explorar as propriedades terapêuticas das plantas e produzir medicamentos; a existência de conhecimentos, além do científico, mas tão importantes e válidos quanto para a nossa compreensão do ambiente a nossa volta; aprofundamento em características botânicas, especialmente as que explicam sua utilização para aliviar dores; respeito à natureza e a ligação que temos com ela (Uganda, 2019 apud Dias, 2019, p. 40).

Tais contribuições são de extrema relevância para área de ensino de Ciências, destacando-se o papel significativo dos conhecimentos etnobiológicos e etnobotânicos na diáspora negra em ações educativas interdisciplinares.

Assim como discutimos anteriormente, os elementos de poder contidos na enunciação das vozes e das linguagens da literatura brasileira, geradores de marginalização e ocultação, podemos também relacionar tais questões, ao considerar ciência como linguagem, com a própria forma de produzir e ensinar Ciências, ainda centrada em referenciais ocidentais e com pouco ou nenhum diálogo com outras formas de conhecimento sobre a natureza e o ambiente, tais como os conhecimentos oriundos das diversas populações tradicionais/originárias. ${ }^{1}$

Acreditamos que o conto $O$ terreiro de vovó Estela, nosso pedacinho de África, ao tematizar contribuições e saberes tradicionais de matrizes africanas, problematizar o racismo e a intolerância e valorizar uma imagem positiva sobre a diáspora, pode ter uma significativa potencialidade não só no ensino de Ciências, mas em todas as áreas, disciplinas e variados contextos educativos que se permita o trabalho, para além dos estereótipos e preconceitos, com as questões e os conceitos postos pelas Leis $\mathrm{n}^{\circ} 10.639 / 2003$ e $\mathrm{n}^{\mathrm{o}} 11.645 / 2008$.

\section{Estrutura, linguagem e público-alvo}

Na categoria estrutura e linguagem, identificamos dois itens (2.1 e 2.4) com avaliação não satisfatória. No caso do item 2.4, dois(duas) juízes(as)/leitores(as) indicaram que a afirmação não se aplica. Nesse caso em específico, a utilização de tópicos pode não favorecer o aprendizado em si, no entanto, não há uma avaliação escrita de que esses devem ser retirados ou reformulados.

O outro item (2.1) refere-se à afirmação de que o nível de leitura é adequado à compreensão do leitor. Além de não haver uma avaliação satisfatória com relação a esse quesito, os sujeitos da pesquisa demonstraram, por meio dos comentários escritos, uma preocupação com relação à faixa etária para a qual se destina a narrativa. A escritora,
Cobern e Loving (2001), consideram que em todo o mundo, onde a ciência é ensinada, é ensinada em detrimento do conhecimento não-ocidental e isso precipita acusações de hegemonia epistemológica e do imperialismo cultural. 
professora e contadora de história Namíbia (2019 apud Dias, 2019, p. 42) considera preocupante:

[...] a faixa etária e a apropriação do texto pelo leitor/contador. $\mathrm{Na}$ minha experiência profissional textos longos, com tantos temas diversos e pouco discutidos socialmente (como é o caso da importância do sagrado nas religiões de matriz africana, uma vez que ainda embrionários, lutamos para combater o racismo religioso) fazem com que as crianças pequenas percam o interesse e a atenção rapidamente por desconhecerem previamente algumas informações [...]. Por isso considero a faixa etária extremamente importante, para crianças a partir de 10 anos.

A leitora/avaliadora traz uma reflexão necessária, destacando uma dificuldade possivelmente enfrentada no âmbito da prática de leitura e contação de histórias para crianças não leitoras, pela extensão do texto e das temáticas abordadas. Além de avaliar, Namíbia propõe uma faixa etária a ser direcionada, confluindo com o que Zimbabwe (2019 apud Dias, 2019, p. 43) afirma:

A linguagem do conto está mais para juvenil, em alguns momentos balança entre uma linguagem muito acessível a nível de compreensão, mas em alguns momentos fica uma linguagem como fosse para o professor, ou o adulto, ou o narrador, acho que seria mais adequado um ritmo linear.

Na mesma perspectiva propositiva, Quênia (2019 apud Dias, 2019, p. 43) recomenda "[...] a troca de algumas palavras para facilitar a compreensão por crianças, pois existem termos que não fazem parte do contexto do universo delas". Tais considerações e recomendações são de grande relevância para pensar melhor sobre o uso da narrativa em contextos de ensino para crianças e dialoga com outro resultado de avaliação não satisfatória referente ao item 3.4, do critério potencial e relevância, que versa sobre a afirmação da viabilidade de contação da história para crianças não leitoras e teve baixo IVC $(0,69)$. Logo, enfatiza-se a necessidade de definir uma faixa etária para o público-alvo e revisar a escrita e a linguagem com as recomendações apontadas. Estamos de acordo que, em uma perspectiva crítica de letramento, deve-se romper com a visão segregadora entre o sujeito que aprende, o processo de aquisição da linguagem e a formação sociocultural e crítica do mundo.

\section{Diáspora, ancestralidade e potencial educativo da tessitura}

A despeito de tais considerações, a recepção do conto, traduzida pelo processo de validação de conteúdo por meio da concordância dos(as) juízes(as)/leitores(as), medida pelo IVC, demonstra uma avaliação satisfatória a nível de categoria e a nível global (Tabela 1). O IVC global do conto foi de 0,91, indicando um excelente nível de concordância entre os avaliadores, assim como indicado em outros trabalhos da mesma natureza (Borges et al., 2013; Moura et al., 2017), ratificando sua validação de conteúdo junto aos(às) especialistas. O IVC de cada categoria também 
foi satisfatoriamente avaliado, tendo sido obtidos valores de 0,92 para conteúdo e objetivo, 0,80 para estrutura e linguagem e 0,84 para potencial e relevância.

Indo além dos dados numéricos, façamos uma reflexão sobre a contribuição da narrativa na visão dos(as) leitores(as) especialistas e em diálogo com a literatura, os(as) quais destacaram potencialidades significativas no âmbito do ensino sobre diásporas, ancestralidade, identidade e valores afro-brasileiros. Na opinião de Malawi (2019 apud Dias, 2019, p. 45):

A historinha de Luanda e sua família representada no conto de forma singela e cativante, navega nesse sentido, ao tratar de temas importantes e atuais sobre a diáspora de forma clara e desmitificada, trazendo para o universo infanto-juvenil uma possibilidade de reflexão de forma leve e crítica. Livros dessa natureza, onde os personagens se apresentam com graça, inteligência e beleza reforçam a auto-estima de crianças negras onde podem encontrar representatividade nos espaços até então negados ou estereotipados.

Todo texto literário escrito ou narrado permite a construção de personagens a partir de sua descrição adjetiva e do conflito em que eles se encontram inseridos e, sobretudo, de sua posição e suas atitudes nesse conflito, atuando, assim, na construção ideológica de cada sujeito (Arboleya, 2013) e na construção, negação e/ou fortalecimento de identidades. A história de Luanda, como reiterado pela especialista, traduz, segundo sua narrativa, influências na concepção estética, intelectual e no sentido de beleza da criança negra, contribuindo dessa forma para a (re)construção de identidades étnicas e raciais historicamente negadas e silenciadas nos espaços escolares e em materiais educacionais.

Elucidando essa questão, ao levar em consideração a identidade étnica e cultural e a própria imagem que se constrói de cada personagem a partir de sua experiência no enredo da história (Arboleya, 2013), vejamos o início da narrativa que destaca a ancestralidade da protagonista no contexto da diáspora:

Luanda é uma menina risonha, carinhosa e que ama os animais, as flores, as plantas e tudo que a faz lembrar e sentir a natureza.

Seu nome é uma homenenagem a sua bisavó paterna, Luanda Nzinga, que veio de Angola, na Africa, onde era uma líder muito corajosa. De tão guerreira e justa, se tornou uma grande representante de seu povo.

Todas as manhãs, sua avó Estela costuma chamar Luanda, dizendo, enquanto acaricia seus pés:

- Acorda minha menina-flor, meu pedacinho de África! [...] (Dias; Souza, 2020, no prelo).

Tal escrita orienta leitores(as) e ouvintes para a referência familiar de resistência africana da pequena Luanda, inscrita na história e no seu próprio nome. Segundo o especialista Lesoto (2019 apud Dias, 2019, p. 46):

Luanda Nzinga, achei excelente a escolha do nome, ele em si, já possibilita desdobramentos sobre a capital de Angola, a Rainha Guerreira Nzinga Mbandi e sobre Ancestralidade - o primeiro nome da Menina-Flor era de sua bisavó. 
No decorrer da narrativa, observa-se melhor essa relação familiar e os motivos pelos quais vieram do outro lado do Atlântico:

[...] De volta à sombra da árvore que fica no meio do terreiro, vovó Estela, emocionada revela:

- Essa majestosa árvore é uma jovem baobá de quase noventa anos, assim como eu. Foi trazido da Africa por minha mãe Luanda Nzinga. Ela sempre dizia que essa árvore é nosso elo com o continente africano. E como se fosse nosso cordão umbilical, nos ligando a nosso lugar primeiro, nosso chão, nosșo terreiro. A raiz nos liga, por debaixo do oceano Atlântico com a Africa, nutrindo o tronco dessa árvore com resistência e memória que ramificam-se em galhos e folhas a ponto de fazer essa agradável sombra. Ela é a mão da terra-mãe acariciando nossa cabeça, guardando nosso corpo e nossa história. E a vida guardando vidas.

- Esse baobá foi trazido por minha mãe Nzinga quando ela teve que vim para o Brasil, aqui para a Bahia, aqui mesmo no Recôncavo, num momento muito difícil. Ela era casada com meu pai e ele veio para ensinar tudo que sabia sobre arquitetura e engenharia. Minha mãe não queria ficar distante de sua terra, mas como ela amava muito meu pai Bazú e estava ficando muito doente de banzo, por conta dessa saudade, acabou vindo [...] (Dias; Souza, 2020, no prelo).

A relação afetiva com o continente africano na fala da avó de Luanda destaca uma memória e uma identidade sobre a diáspora para além da visão reducionista que resume esse processo à escravidão. No lugar de memórias sobre violência, cativeiro ou navios negreiros, reforça-se uma ligação de orgulho, identidade racial fortalecida, de relação umbilical, e, portanto, maternal, visceral e necessária enquanto subsistência das tradições. A metáfora da raiz do baobá demonstra o quão radicalmente a diáspora é representada no conto, traduzida também pelo cultivo de valores, atitudes, saberes e sentimentos ancestrais, como bem expressa Moçambique (2019 apud Dias, 2019, p. 47):

Acredito serem as narrativas orais da tradição afro-brasileira e indígena, uma das muitas estratégias para o ensino de valores, conhecimentos de utilização e preservação da natureza e, principalmente do respeito para com os mais velhos, verdadeiros detentores dos saberes e fazeres dos nossos ancestrais.

Recuperar o valor da tradição oral na nossa cultura ocidental é outra contribuição significativa da narrativa, assim, mostra-se como estratégia poderosa para o ensino de história e cultura africana e afrodiaspórica. Como nos elucida Lisoto (2019 apud Dias, 2019, p. 47):

O texto de forma sutil e envolvente apresenta questões essenciais para compreender inicialmente uma estrutura de sociedade pautada em outros valores. Tais como: arerê, Ossaim, Ervas (propriedades), Orixás, Cabaça, Terreiro, Axé, Baobá (nossas raízes com Africa), a cantiga, feijoada (Ogum), a passagem de conhecimento através da oralidade, a preservação da natureza [...] e a intolerância/racismo.

Sabemos que a oralidade é uma das características fundamentais da cultura africana, especialmente nas sociedades tradicionais, é um modo 
de ser (Machado, 2013). Segundo Vanda Machado (2013, p. 61), podemos considerá-la, na atualidade, "como um importante instrumento metodológico para reconstituição e continuidade da história local, imprescindível para a conservação da tradição, dos mitos, das lendas". É por meio dessa oralidade que a palavra se faz elemento produtor da história, potencializando assim o papel educativo e transformador de tecer, de escrever, de contar e de ouvir histórias sobre ancestralidade e cosmovisão africanas.

Na visão de Eduardo de Oliveira (2012), ancestralidade é uma categoria capaz de dialogar com a experiência negro-africana em solo brasileiro, que mantém e atualiza sua forma cultural na capoeira angola e no Candomblé tradicional, por exemplo. Assim, diáspora, oralidade e ancestralidade se entrelaçam no tecer educativo que se propõe a tematizar relações étnicoraciais desde a África, como a narrativa protagonizada por Luanda e sua avó.

Uma sugestão importante para o conto foi levantada por alguns dos especialistas, a da necessidade de referenciar e circunstanciar o uso de nomes, como o da própria Luanda Nzinga e de Bintou, personagem do livro infantojuvenil As Tranças de Bintou (Diouf, 2004). Além de citar tais referências, é importante situar historicamente, já que o nome fictício de Nzinga pode ser confundido com nomes reais de contextos históricos distantes. Portanto, merece atenção na própria narrativa e no seu uso em contexto de ensino. Um glossário de termos, nomes e conceitos que não são inteligíveis para o grande público de crianças e jovens pode preencher essa lacuna da narrativa.

\section{À guisa de conclusão}

A propulsão deste trabalho reside, principalmente, no desejo de qualificar a prática educativa voltada para o ensino de história e cultura africana e afrodiaspórica. Para tanto, como forma de otimizar um processo investigativo a longo prazo e para que este resulte em transformações efetivas de contextos educativos e formativos de docentes e discentes, escolhemos o caminho da pesquisa-ação, que teve como primeira etapa a concepção e a recepção de um produto literário infantojuvenil, apresentada e discutida neste artigo. Esta proposta esteve envolta pela preocupação de produzir um material educativo e, ao mesmo tempo, colocá-lo em pauta para crítica de professores(as), pesquisadores(as) e escritores(as), no sentido de identificar contribuições, limitações, rupturas e continuidades da escrita literária infantojuvenil afro-brasileira.

Com base na interpretação dos dados, podemos considerar que o conto O terreiro de vovó Estela, nosso pedacinho de África foi devidamente validado pelos(as) especialistas participantes, com contribuições significativas para a educação das relações étnico-raciais no tocante à representação do continente africano e do processo diaspórico para além dos estereótipos reducionistas, ao enaltecimento da beleza negra, dos saberes ancestrais 
e dos conhecimentos tradicionais, ao resgate da oralidade e dos valores afro-brasileiros, à abordagem didática sobre a religiosidade de matriz africana, além da mitologia, da musicalidade e da ancestralidade como centralidade da narrativa.

A proposta é que este trabalho se desdobre na continuidade de uma pesquisa-ação, a qual tenha como horizonte a implementação da narrativa em salas de aula e em outros espaços de sociabilidades educativas, como terreiros de Candomblé. Assim, envolver outros sujeitos, como as próprias crianças e os jovens, se torna imperativo. Nesse aspecto, cabe aos autores estabelecer melhor o público para o qual se destina a história de Luanda e sua avó Estela, rever as ponderações postas por essa investigação e dar continuidade ao processo de criação, pesquisa e publicação da obra.

\section{Referências}

ARBOLEYA, V. J. O negro na literatura infantil: apontamentos para uma interpretação da construção adjetiva e da representação imagética de personagens negros. Geledés, [São Paulo], mar. 2013. Patrimônio Cultural. Disponível em: <https://www.geledes.org.br/o-negro-naliteratura-infantil-apontamentos-para-uma-interpretacao-da-construcaoadjetiva-e-da-representacao-imagetica-de-personagens-negros/ > . Acesso em: 12 jul. 2021.

BORGES, J. W. P. et al. Validação de conteúdo das dimensões constitutivas da não adesão ao tratamento da hipertensão arterial. Revista da Escola de Enfermagem, São Paulo, v. 47, n. 5, p. 1077-83, out. 2013.

BRASIL. Lei $\mathrm{n}^{\circ}$ 10.639, de 9 de janeiro de 2003. Altera a Lei no 9.394, de 20 de dezembro de 1996, que estabelece as diretrizes e bases da educação nacional, para incluir no currículo oficial da rede de ensino a obrigatoriedade da temática "História e Cultura Afro-Brasileira", e dá outras providências. Diário Oficial da União, Brasília, DF, 10 jan, 2003. Seção 1, p. 1.

BRASIL. Lei $\mathrm{n}^{\circ}$ 11.645, de 10 de março de 2008. Altera a Lei $\mathrm{n}^{\circ}$ 9.394, de 20 de dezembro de 1996, modificada pela Lei ${ }^{\circ}$ 10.639, de 9 de janeiro de 2003, que estabelece as diretrizes e bases da educação nacional, para incluir no currículo oficial da rede de ensino a obrigatoriedade da temática "História e Cultura Afro-Brasileira e Indígena". Diário Oficial da União, Brasília, DF, 13 mar. 2008. Seção 1, p. 1.

BRASIL. Ministério da Educação (MEC). Plano Nacional das Diretrizes Curriculares Nacionais para a Educação das Relações Étnico-Raciais e para o ensino de História e Cultura Afro-Brasileira e Africana. Brasília, DF: MEC, 2009. 
CAVALLEIRO, E. S. Do silêncio do lar ao silêncio escolar: racismo, preconceito e discriminação na educação infantil. São Paulo: Contexto, 2000 .

COBERN, W.; LOVING, C. Defining "science" in a multicultural world: implications for science education. Science Education, [S.1.], v. 85, n. 1, p. 50-67, Jan. 2001.

CRESWELL, J. W. Projeto de pesquisa: métodos qualitativo, quantitativo e misto. 2. ed. Porto Alegre: Bookman, 2010.

DIAS, T. L. S. O terreiro de vovó Estela, nosso pedacinho de África: tessitura e avaliação de um produto literário infantojuvenil. 2019. 64 f. Trabalho de Conclusão de Curso (Especialização em Estudos Étnicos e Raciais) - Instituto Federal de Educação, Ciência e Tecnologia, Salvador, 2019.

DIAS, T. L. S.; SOUZA, R. S. A Diáspora Africana em um produto autoral de literatura infanto-juvenil. In: ENCONTRO NACIONAL DOS NEAB, NEABI E GRUPOS CORRELATOS DA REDE FEDERAL, 4., 2018, Salvador. Anais eletrônicos... Salvador: Instituto Federal de Educação, Ciência e Tecnologia Baiano, 2018. p. 140-145. Disponível em: <https:// enneabi.ifbaiano.edu.br/wp-content/uploads/2020/05/Anais-do-IVENNEABI-e-II-RENEABI-educa\%C3\%A 7\%C3\%A3o-e-diversidade-etnica. pdf $>$. Acesso em: 9 jul. 2020.

DIAS, T. L. S.; SOUZA, R. S. Literatura infanto-juvenil, etnociências e religiosidade de matriz africana. In: SEMINÁRIO GRIÔ, 2., 2017. Salvador. Anais... Salvador: Universidade Federal da Bahia, 2017.

DIAS, T. L. S.; SOUZA, R. S. O terreiro de vovó Estela, nosso pedacinho de África. Salvador, 2020. No prelo.

DIOUF, S. A. As tranças de Bintou. São Paulo: Cosac \& Naif, 2004.

EVARISTO, C. Literatura negra: uma poética de nossa afrobrasilidade. SCRIPTA, Belo Horizonte, v. 13, n. 25, p. 17-31, 2ºm. 2009.

FLEURY, M. T. L; WERLANG, S. R. da C. Pesquisa aplicada: conceitos e abordagens. Anuário de Pesquisa GVPesquisa: 2016: 2017. [São Paulo], 2017. Disponível em: <http://bibliotecadigital.fgv.br/ojs/index.php/ apgvpesquisa/issue/view/4030/1982>. Acesso em: 9 jul. 2021.

FREITAS, I. S. O ponto e a encruzilhada: a poesia negra rasurando a memória, a história e a literatura oficial através da intertextualidade. 2015. $221 \mathrm{f}$. Tese (Doutorado em Letras) - Instituto de Letras,

Universidade Federal da Bahia, Salvador, 2015. 
GEVEHR, D. L.; ALVES, D. Educação étnico-racial na escola: a Lei 10639/2003 e os desafios da interdisciplinaridade para além das aulas de história. Ágora, Santa Cruz do Sul, v. 17, n. 2, p. 17-30, jul./dez. 2016.

GOMES, N. L. Cultura negra e educação. Revista Brasileira de Educação, Belo Horizonte, n. 23, p. 75-85, ago. 2003.

GOMES, N. L. Práticas pedagógicas de trabalho com relações étnicoraciais na escola na perspectiva da Lei $n^{o}$ 10.639/03. Brasília: Unesco, 2012.

ISER, W. O ato da leitura: uma teoria do efeito estético. Tradução de Johannes Kretschmer. São Paulo: Editora 34, 1996.

KOCH, I. V.; ELIAS, V. M. Ler e compreender: os sentidos do texto. 2 ed. São Paulo: Contexto, 2006.

MACHADO, V. Pele da cor da noite. Salvador: Editora da Universidade Federal da Bahia, 2013.

MOURA, I. H. de. et al. Construção e validação de material educativo para prevenção de síndrome metabólica em adolescentes. Revista LatinoAmericana de Enfermagem, Ribeirão Preto, v. 25, out. 2017.

NOA, F. As falas das vozes desocultas: a literatura como restituição. In: GALVES, C. et al. (Org.). África-Brasil: caminhos da língua portuguesa. Campinas: Editora da Universidade Estadual de Campinas, 2009. p. 85-100.

NOBRE, R. de S. Construção e validação de uma tecnologia educativa sobre promoção da cultura do aleitamento materno em escolares. 2018. 128 f. Dissertação (Mestrado em Ciências e Saúde) - Centro de Ciências da Saúde, Universidade Federal do Piauí, Teresina, 2018.

NOFFKE, S.; BRIDGET, S. Action Research. In: SOMEKH, B.; LEWIN, C. Research Methods in Social Sciences. London: Sage Publications, 2005. p. 89-96.

OLIVEIRA, E. D. Filosofia da ancestralidade como filosofia africana: educação e cultura afrobrasileira. Revista Sul-Americana de Filosofia e Educação, Brasília, n. 18, maio/out. 2012.

OLIVEIRA, M. A. J. Literatura afro-brasileira infanto-juvenil: enredando inovação em face à tessitura dos personagens negros. In: CONGRESSO INTERNACIONAL DA ABRALIC, 11., 2008, São Paulo. Anais... São Paulo: USP, 2008. Disponível em: <http://www.abralic.org.br/eventos/ cong2008/AnaisOnline/simposios/pdf/024/MARIA_OLIVEIRA.pdf $>$. Acesso em: 9 jul. 2021. 
OLIVEIRA, M. A. J. Personagens negros na literatura infanto-juvenil no Brasil e em Moçambique (2000-2007): entrelaçando vozes tecendo negritudes. 2010. 301f. Tese (Doutorado em Letras) - Centro de Ciências Humanas, Letras e Arte, Universidade Federal da Paraíba, João Pessoa, 2010 .

OLIVEIRA, M. A. J. Áfricas e diásporas na literatura infanto-juvenil no Brasil e em Moçambique. Salvador: Editora da Universidade do Estado da Bahia, 2014.

PASQUALI, L. Psicometria. Revista da Escola de Enfermagem, São Paulo, v. 43, n. esp. p. 992-999, 2009.

PESTANA, P. S. Estereótipos e inovações em "Nó na garganta" e "A cor da ternura". Scripta Alumni, v. 2, p. 50-70, dez. 2009.

PILATTI, L. A.; PEDROSO, B.; GUTIERREZ, G. L. Propriedades Psicométricas de Instrumentos de Avaliação: um debate necessário. Revista Brasileira de Ensino de Ciência e Tecnologia, Ponta Grossa, v. 3, n. 1, jan./abr. 2010.

RAYMUNDO, V. P. Construção e validação de instrumentos: um desafio para a psicolinguística. Letras de Hoje, Porto Alegre, v. 44, n. 3, p. 86-93, jul./set. 2009.

SANTANA, J.; BAIBICH-FARIA, T. M.; PESSOA, C. F. A lei n. ${ }^{\circ} 10.639$ e a folclorização racista. Revista Eletrônica Pesquiseduca, Santos, v. 2, n. 3, jan./jun. 2010.

SILVA, A. C. A discriminação do negro no livro didático. 2 ed. Salvador: Editora da Universidade Federal da Bahia, 2004.

SILVA, A. C. A desconstrução da discriminação no livro didático. In: MUNANGA, K. (Org.). Superando o racismo na escola. 2 ed. Brasília: MEC/Secadi, 2005. p. 21-37. Disponível em: <https://www. livrariapublica.com.br/2019/04/superando-o-racismo-na-escolakabengele.html>. Acesso em: 17 jan. 2018.

SILVA JÚNIOR, S. D.; COSTA, F. J. Mensuração e escalas de verificação: uma análise comparativa das escalas de Likert e Phrase Completion: PMKT. Opinião e Mídia: revista brasileira de pesquisas de marketing, São Paulo, v. 15, p. 1-16, out. 2014.

SOUZA, A. L.; SOUSA, A. L.; PIRES, R. A. Afro-literatura brasileira: o que é? para que serve? como trabalhar? subsídio: uma ideia para o dirigente municipal de ensino. Gruhbas: Projetos Educacionais e Culturais, São Paulo, v. 12, n. 12, p. 3-4, 2005. 
TELES, L. M. R. et al. Construção e validação de manual educativo para acompanhantes durante o trabalho de parto e parto. Revista da Escola de Enfermagem da USP, São Paulo, v. 48, n. 6, p. 977-984, dez. 2014.

TRIPP, D. Pesquisa-ação: uma introdução metodológica. Educação e Pesquisa, São Paulo, v. 31, n. 3, p. 443-466, set./dez. 2005.

ZILBERMAN, R. Recepção e leitura no horizonte da literatura. ALEA, Rio de Janeiro, v. 10, n. 1, p. 85-97, jan./jun. 2008.

Recebido em 20 de março de 2020.

Aprovado em 25 de março de 2021. 